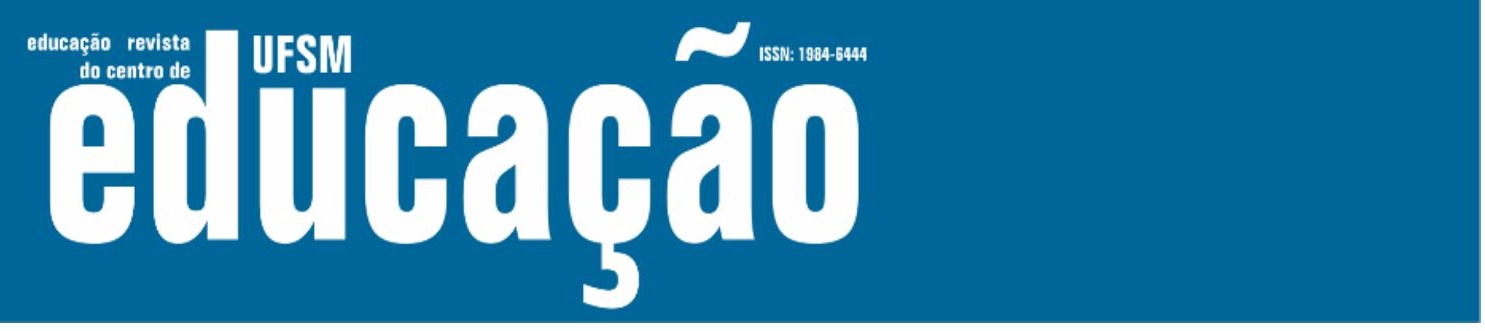

ISSN: 1984-6444 | http://dx.doi.org/10.5902/1984644441514

\title{
Competências desenvolvidas no processo de formação profissional dos técnicos de enfermagem da região sul do Rio Grande do Sul
}

\author{
Skills developed in the professional training process of nursing \\ technicians in the south region of Rio Grande do Sul
}

Carla Regina Andre Silva

Enfermeira no Instituto Federal de Educação, Ciência e Tecnologia do Rio Grande do Sul, Rio Grande, Rio Grande do Sul, Brasil.

carla.andre@riogrande.ifrs.edu.br - https://orcid.org/0000-0002-8050-2400

Deise Lima Righi, Marlene Teda Pelzer

Coordenadora dos cursos técnicos em enfermagem na instituição SENAC - Sistema Nacional de Aprendizagem Comercial. Rio Grande, Rio Grande do Sul, Brasil.

deisenfermagem@gmail.com - https://orcid.org/0000-0002-0571-4489

Recebido em 02 de junho de 2020

Aprovado em 15 de junho de 2020

Publicado em 30 de junho de 2021

\section{RESUMO}

Estudo desenvolvido nos cursos Técnicos de Enfermagem da região sul do estado do Rio Grande do Sul, objetivando analisar o processo de formação profissional formal dos futuros técnicos em enfermagem, nesta localidade, se faz por meio do desenvolvimento de competências, assim como conhecer as competências que estão sendo desenvolvidas nestes cursos. O significado sobre desenvolvimento de competências no âmbito educacional e profissional está alicerçado nas ideias de Philippe Perrenoud. A metodologia é uma abordagem qualitativa, de natureza exploratória e caráter descritivo. A coleta dos dados primários foi mediada pela aplicação de instrumento semiestruturado, com perguntas abertas e fechadas, aos discentes e docentes, no segundo semestre de 2018. E os dados secundários foram obtidos através de pesquisa documental. $O$ estudo foi desenvolvido em quatro instituições distribuídas em três municípios, participando 64 discentes e cinco docentes. Os resultados foram extraídos com base no método de análise de conteúdo. Foram encontrados elementos constitutivos que indicam que o processo formativo nestes espaços está alicerçado nas noções de competências de acordo com referencial teórico adotado. Assim, o processo de ensino aprendizagem ao contemplar o desenvolvimento de competências, adquire um sentido mais amplo do que apenas a formação profissional e inserção no mercado de trabalho. Tem como possibilidades a contribuição com a produção de saúde individual, coletiva e pública e formação humana e cidadã de seus integrantes.

Palavras-chave: Enfermagem; Educação baseada em competências; Técnico de Enfermagem. 


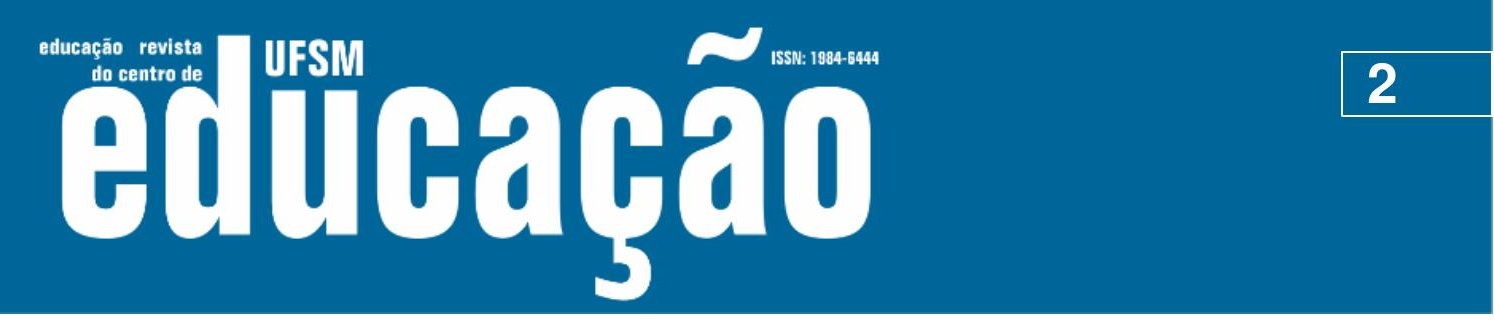

ISSN: 1984-6444 | http://dx.doi.org/10.5902/1984644441514

\section{ABSTRACT}

Study developed in the Technical Nursing courses in the southern region of the state of Rio Grande do Sul, aiming to analyze the process of formal professional training of future nursing technicians in this location, it is done through the development of skills, as well as knowing the skills that are being developed in these courses. The meaning of skills development in the educational and professional fields is based on the ideas of Philippe Perrenoud. The methodology is a qualitative approach, exploratory and descriptive. The collection of primary data was mediated by the application of a semistructured instrument, with open and closed questions, to students and teachers, in the second semester of 2018. And the secondary data were obtained through documentary research. The study was developed in four institutions distributed in three municipalities, with 64 students and five teachers participating. The results were extracted based on the content analysis method. Constitutive elements were found that indicate that the training process in these spaces is based on the notions of competences according to the adopted theoretical framework. Thus, the teachinglearning process, when considering the development of skills, takes on a broader meaning than just professional training and insertion in the labor market. It has as possibilities the contribution to the production of individual, collective and public health and human and citizen training of its members.

Keywords: Nursing; Competence-based education; Nursing technician.

\section{Introdução}

A educação profissional no Brasil é uma premissa assegurada na Constituição Federal de 1988 em seu artigo 227 e na Lei de Diretrizes e Bases da Educação Nacional de 1996, em seu artigo 22. É um direito individual e coletivo do cidadão, e deve ser significativa, preparando os sujeitos para a vida profissional e social ao construir, manter e transformar saberes, valores e conhecimentos de forma sistêmica. Compondo, dessa forma, a teia de relações e inter-relações que envolvem a formação profissional, pessoal, cidadã e influenciando no meio em que vive, trabalha e se desenvolve (BRASIL,1988; 1996 1999; CAPRA, 2012).

A Resolução da Câmara de Educação Básica do Conselho Nacional de Educação (CNE/ CEB) no 04/99 Instituiu as Diretrizes Curriculares Nacionais para a Educação Profissional de Nível Técnico, que é a articulação de princípios, critérios, competências profissionais específicas por área e procedimentos a serem 


\section{Aillbapẫ \\ 3}

ISSN: 1984-6444 | http://dx.doi.org/10.5902/1984644441514

docência no ensino técnico, aceitar em participar do estudo e assinar o Termo de Consentimento Livre e Esclarecido (TCLE).

Os critérios de inclusão para os discentes foram: estar matriculado regularmente no curso, cursando duas ou mais disciplinas da fase final do curso, aceitar em participar do estudo e assinar o TCLE.

A análise dos dados foi de acordo com o método de análise de conteúdo de Bardin (2011), que contempla as etapas: a pré-análise dos dados alicerçados no problema e nos objetivos; a exploração do material por meio da confrontação sistemática e das inferências alcançadas e o tratamento dos resultados.

$\mathrm{Na}$ busca por registros que relacionassem o processo de ensino a ser desenvolvido por competências, foram extraídas dos documentos expressões e palavras chave relacionadas ao tema, pela análise do conteúdo e de acordo com sua adequação, inferência e contexto. Resultando assim na elaboração da primeira categoria.

Para analisar as competências desenvolvidas nos cursos e as correlacionar com a teoria de Perrenoud, os dados foram analisados separadamente $e$ posteriormente agrupados em unidades comparáveis de categorização temática, de acordo com suas características comuns, referencial teórico e revisão bibliográfica, originando as demais categorias.

Para contemplar o anonimato, os participantes foram identificados com as siglas: DO para docentes e DI para discentes, com acréscimo de número arábico.

Foram respeitados os aspectos éticos da pesquisa envolvendo seres humanos contidos na Resolução 466/2012, com aprovação do Comitê de Ética em Pesquisa na Área da Saúde - CEPAS da Universidade Federal do Rio Grande sob o parecer 125/2018.

\section{Resultados e discussões}

O estudo foi desenvolvido em três municípios, em quatro instituições, totalizando 64 discentes e 5 docentes como participantes. 


\section{uss \\ $\sim$

ISSN: 1984-6444 | http://dx.doi.org/10.5902/1984644441514

[...] tratar os conhecimentos como recursos a serem mobilizados para solucionar uma situação-problema, ou seja, exige passar de uma lógica de ensino para uma lógica de construção, baseando-se na premissa de que "constroem-se as competências exercitando-se em situações complexas" (PERRENOUD, 1999, p. 54).

O processo de "saber fazer" e "saber ser", envolve perceber a problemática, selecionar os conhecimentos necessários (teóricos, científicos, técnicos, legais e éticos), organizar o pensamento integrando estes detalhes, considerando o contexto em que se apresentam e os aproximando para gerar a tomada de decisão que resolva o problema.

A noção de competência remete para situações nas quais é preciso tomar decisões e resolver problemas, associa-se à compreensão e avaliação de uma situação, uma mobilização de saberes, de modo a agir/reagir adequadamente. Desta forma, a tomada de decisão (expressar conflitos, oposições), a mobilização de recursos (afetivos e cognitivos) e o saber agir (saber dizer, saber fazer, saber explicar, saber compreender) são as características principais da competência (DIAS, 2010, p. 75).

Dias et al, (2013), em seus estudos, apontou que o ensino por competências já está instituído documentalmente nos cursos Técnicos de enfermagem. Sendo compreendido como a mobilização de habilidades e saberes de experiências anteriores e novas, na busca por resolução de situações-problema.

Ao desenvolver competências, os alunos serão capazes de ter raciocínio crítico perante situações adversas e agir com segurança, e, quando for preciso, tomar decisões pautadas na ética e no conhecimento científico (DIAS et al., 2013, p. 885).

\section{Desenvolvimento de competências profissionais prioritárias}

Nos projetos político pedagógicos e nos planos de cursos encontram-se as indicações que a formação deve ser embasada em uma postura ética, humanizada e conforme as competências necessárias à profissão. No processo de ensino, há elementos constitutivos que norteiam o fazer docente direcionado para construção 


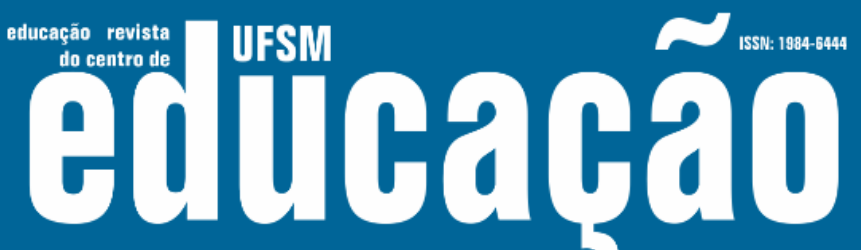

ISSN: 1984-6444 | http://dx.doi.org/10.5902/1984644441514

de conhecimentos, atitudes, valores, por meio de visão interdisciplinar, globalizada e contextualizada, relacionando teoria e prática.

Nestes documentos, a educação é percebida como fonte de exercício de cidadania, embasada em uma postura ética e humanizada. Indicando a importância de ter uma comunicação eficiente, incluindo praticar o escutar, o observar, a emitir, o trabalhar em equipe, a motivação e o prazer para o trabalho. $O$ desenvolvimento pessoal e profissional é visto como produto de um comportamento político, ético e estético acompanhado de autonomia, reflexão do fazer, tomada de decisão, flexibilidade nas situações adversas, evidenciando compreender os comportamentos humanos, respeito aos valores pessoais (seus e dos outros), sociais, culturais, religiosos e empatia. A busca por aprimoramentos deve ser contínua, entendendo que a construção da aprendizagem também se faz por meio de autonomia, com potencial criatividade, articulando competências, habilidades e atitudes (conhecimentos/saber fazer/ saber ser).

Os docentes entendem que o processo de ensino aprendizagem favorece aos discentes a desenvolverem capacidades para articular e colocar em prática valores, conhecimentos e habilidades necessárias para o desempenho das atividades profissionais. O ensino é percebido com o pluri e transdisciplinar, buscando o potencial dos alunos. O processo de ensino aprendizagem contempla trabalho em equipe, uso de novas tecnologias, participação colaborativa dos alunos nos métodos de ensino, enfrentamento dos deveres e dilemas éticos da profissão e transposição da aprendizagem, além da certificação.

\footnotetext{
Acho muito interessante a forma de ensino, é diferente pelo lado bom, todas as professoras trabalham juntas para a nossa melhor aprendizagem (DI 19). Prepara o aluno não apenas para a situações normais/comuns ao dia a dia profissional. Entendo como um caminho a ser buscado, em constante formação (DO 5).

O curso é ministrado em colegiado, o que diversifica e aprimora a formação (DO 4).
}

São características dos processos formativos destes cursos, exigir dos alunos esforços e comprometimento com o processo de aprendizagem no dia a dia e não 


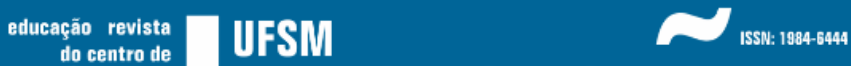

ISSN: 1984-6444 | http://dx.doi.org/10.5902/1984644441514

somente nas avaliações formais, preparando-os para além das situações cotidianas pessoais e profissionais.

Sobre o processo de ensino penso que as alternativas são proporcionadas nas diferentes situações que se apresentam, não de forma concomitante, mas são propiciadas em diversos momentos [...] o ensino visa contemplar diversas esferas, porém nem sempre atinge, pois esse processo envolve 0 docente $e$ o estudante e todas as disponibilidades desses precisam estar em consonância no processo (DO 4).

[...] aulas voltadas ao aprendizado científico, ético e legal (DI 22).

A aprendizagem é avaliada por meio observacional e outros critérios, além das avaliações tradicionais (provas), É utilizada problematização para concretização do ensino, que no decorrer do processo vai se tornando mais complexa. Nestas situações problema são incluídos os conhecimentos teóricos, práticos, éticos, sobre humanização e outros. Os docentes ainda relataram que o processo de avaliação dos cursos contempla a participação ativa dos alunos, e que esta etapa é a mais complexa em todo o processo de ensino e que é fornecido apoio integrado para os alunos que apresentam dificuldades.

É avaliado a participação ativa do aluno no decorrer do curso (DO 1).

Avaliar é sempre muito complicado, estamos constantemente reavaliando nossas fichas e metodologias de avaliação, anualmente se apresentam diferentes alunos, com diferentes perfis e necessidades (DO 4).

As atividades didáticas dos cursos constituem-se no sentido da formação e adequadas às características individuais e coletivas dos alunos. São oportunizadas atividades de iniciação científica por meio de estágios não curriculares em campos de atuação profissional. O processo de ensino aprendizagem proporciona aprender a aprender, a resolução de problemas (fazer), a ter espírito investigatório (conhecer), a resolução de conflitos (conviver), a assumir as responsabilidades por meio do exercício de autonomia (ser), a compreender a realidade e contribuir com a sociedade e vida profissional (aprendizagem voltada para a vida). Associando 


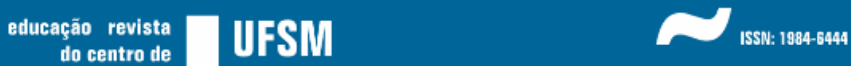

ISSN: 1984-6444 | http://dx.doi.org/10.5902/1984644441514

saberes que podem ser aplicados para a vida. Favorece o relacionar conhecimentos de diferentes áreas e viabilizar um fazer consciente e contextualizado.

O estudante se depara com a situação e são discutidos o máximo de aspectos que envolvem a situação e as possibilidades de atuação (DO 5). Ensino extremamente bem estruturado e "forte', acontece aprendizagem e em contrapartida e cobrado o esforço e dedicação diários dos alunos (DI 16).

$\mathrm{Na}$ sua atuação profissional, percebem a possibilidade de exercitar a autonomia, de renovar e planejar suas aulas, por meio de ações desafiadoras, articulando conhecimentos já desenvolvidos com os que estão sendo trabalhados, relacionando os conhecimentos que estão a trabalhar com diferentes áreas sem perder o objetivo principal. Ainda, confirmaram ser realizado o contrato didático e que este pode ser ajustado de acordo com as necessidades de forma colaborativa. No contrato são vislumbradas as diferentes possibilidades de aprendizagem e normas de forma integral, global, científica, ética e legal.

Sobre o contrato didático, se pensarmos conjuntamente (docentes e discentes) em possibilidades de realizar, organizar, é alterado em consenso (DO 4).

Assim, formar profissionais técnicos em enfermagem para o trabalho não é mais instrumentalizar mão de obra, e, sim, formar profissionais autônomos, críticos e competentes para atuar no campo da saúde que passa por constantes transformações (DIAS et. al, 2013, p,889).

Os discentes pontuaram que o processo de ensino aprendizagem favorece o desenvolver de capacidades de maneira articulada, e coloca em prática valores, conhecimentos e habilidades necessárias para o desempenho das atividades profissionais, buscando o potencial dos alunos.

[...] além da teoria, à prática acaba nos capacitando mais, trazendo mais confiança para o aluno (DI 10).

As atividades são boas, despertam o interesse em relação o fazer. Para nós alunos, interagir e participar das aulas, trabalhos, projetos e estágios são bons (DI 18). 


\section{$\sim$ ussm,

ISSN: 1984-6444 | http://dx.doi.org/10.5902/1984644441514

Ensino focado na aprendizagem de cada um, para formar um bom profissional (DI 6).

Demonstraram que o objetivo dos estudos está presente em várias disciplinas, e que o conhecimento desenvolvido acontece entre as diferentes disciplinas, indo além do que compõe o currículo. O trabalho em equipe é incentivado, assim como a participação colaborativa nos métodos de ensino. Sentem-se instigados a refletir sobre o enfrentamento dos dilemas éticos profissionais e que esta ação de ensino (transposição didática) ultrapassa o necessário para a certificação. Relataram serem exigidos esforços e comprometimento com a aprendizagem no dia a dia e não somente nas avaliações formais.

O método de ensino é de certa forma reflexivo, nos faz pensar e desenvolver todas as atividades relacionadas ao bem-estar dos nossos futuros usuários de saúde (DI 19).

Muito bom, os professores nos apresentam situações reais, métodos utilizados, procedimentos utilizados, mostrando como funciona na realidade (DI 24).

É passado todo o conteúdo necessário para uma boa formação, misturando prática e teoria ao longo do curso para que possamos vivenciar o aprendizado técnico (DI 39).

As atividades didáticas se constituem com sentido, sendo proporcionadas experiências por meio de atividades de iniciação científica como pesquisa, trabalho de conclusão de curso, extensão, estágios. A aprendizagem é voltada para a vida, pois motiva a aprender a ser, a fazer e a conviver com os outros, associando os saberes que podem ser aplicados não somente no curso, mas vida.

\footnotetext{
Levamos para a vida todos os ensinos e aprendizagem [...] saber agir no meio dos problemas (DI 4).

O ensino levaremos para a vida toda se realmente nos dedicarmos .... é um modo muito eficaz, pois além das aulas teóricas podemos desenvolver nosso conhecimento na prática (DI 8).
} 


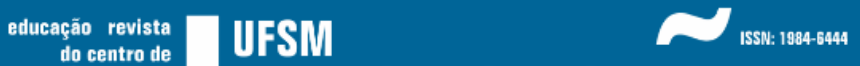

ISSN: 1984-6444 | http://dx.doi.org/10.5902/1984644441514

Aulas práticas e teoria que fazem com que nós elaboramos da nossa forma o conhecimento, de nosso jeito, mas o entendimento baseado com o que foi dado em sala de aula (DI 48).

As avaliações são feitas com base nos conteúdos passados e de acordo com a evolução dos alunos (DI 39).

Os discentes avaliaram que os docentes têm autonomia nas aulas, as planejam, e possuem domínio das áreas que atuam e demonstram capacidade de correlação dos conhecimentos que estão a trabalhar com diferentes áreas sem perder o objetivo principal e articulam os conhecimentos já desenvolvidos com os que estão sendo trabalhados. Afirmaram que é realizado contrato didático entre educandos e educadores de forma colaborativa entre as partes, incluindo neste contrato questões referentes ao ensino voltado à aprendizagem para a vida e normas sobre o processo de ensino de forma integral.

\footnotetext{
Ensino complexo, nos motivando com que se busque outras fontes de conhecimento (DI 40).

Ensino amplo, aulas com participação ativa dos alunos, aulas práticas com avaliações antes do campo de estágio (DI 46).
}

Competências vão além de conhecimentos "são possibilidades de relacionar, pertinentemente, os conhecimentos e os problemas" (PERRENOUD, 1999, p. 33).

O desenvolvimento de competências está relacionado a uma singularidade das pessoas envolvidas e da situação em si, em um contexto particular que condiciona o acesso às informações pertinentes (científicas, técnicas, éticas, legais), capacidades mentais, cognitivas, afetivas e as singularidades dos indivíduos (experiências de vida e conhecimentos construídos previamente), que conduzem a uma interpretação da realidade. Assim, a lógica da integração dos saberes, do saber fazer e dos comportamentos estabelecem-se em função das exigências situacionais, desencadeando na tomada de decisão e resolução do problema (MACHADO, 2016). 


\section{Eulthapẫ}

ISSN: 1984-6444 | http://dx.doi.org/10.5902/1984644441514

\section{Desenvolvimento de competências profissionais específicas}

Nos documentos foram encontradas referências sobre Competências profissionais específicas como: formar profissionais capazes de relacionar os conhecimentos teóricos, teórico-práticos e práticos. Ainda, promover reflexões sobre o papel do TE no contexto profissional e social como estratégia para soluções de problemas relacionadas à prática profissional (aprendizagem centrada na problematização). Suprir as demandas do mercado de trabalho na área com profissionais competentes. Realização de estágios curriculares capazes de desenvolver competências e habilidades iguais ou semelhantes às do mercado de trabalho e necessárias a conclusão do curso com a finalidade de proporcionar condições para a integração dos TE neste mercado. Formar profissionais que compreendam e busquem a permanente construção de sua identidade pessoal e profissional com o intuito de aprimoramentos do desempenho e da qualidade profissional.

Sobre as competências específicas do TE, foram encontrados registros como cuidados com a saúde dos indivíduos e coletividades, para atuar em hospitais, escolas, empresas, unidades básicas de saúde, Programa Saúde da família, Centros de Apoio Psicossociais, em todos os ciclos da vida e morte juntamente com equipe multiprofissional. Formar profissionais com competências para realizar cuidado humano e ético, conhecer as leis do exercício profissional, respeito às limitações da atuação profissional e sigilo, ter uma comunicação efetiva com os usuários/familiares dos serviços de saúde e equipe de trabalho, respeito à vida, à dignidade e aos direitos das pessoas.

Os docentes afirmaram que no processo de formação é possibilitado ao discente observar, analisar, fazer, refletir, ouvir e falar. Para Perrenoud (1999), competências são construídas e adquiridas, portanto não são objetivos, nem indicadores de desempenho e tão pouco potencialidades da mente humana, pois estas só se tornam competências através de aprendizagem desenvolvida.

O nível de atenção à saúde que o curso mais enfatiza é atenção primária e secundária. Os discentes são instrumentalizados para prestar o cuidado integral ao 


\section{usm

ISSN: 1984-6444 | http://dx.doi.org/10.5902/1984644441514

ser humano, porém os cursos favorecem mais a atuação profissional nas áreas do indivíduo adulto clínico e cirúrgico, e menos para atuação em urgência e emergências e saúde mental. Os docentes compartilham da ideia de que os alunos ao final do curso têm condições de atuar em qualquer área, contemplando todos os ciclos da vida.

O grupo de professoras possui uma excelente formação profissional e se mantém atento ao aspecto para os futuros TE terem formação para atuarem em diferentes áreas com conhecimentos. São feitas reuniões semanais para atualização e formação profissional das docentes [...] (DO 5).

O curso nos proporciona garantir o cuidado integral a saúde, bem-estar ao paciente em diferentes fases da vida (DI 43).

Observar, analisar, prestar o cuidado (DI 44).

Relataram que os discentes são instigados parcialmente a relacionar os conhecimentos formativos com o cotidiano real, com os conteúdos atuais, culturais, sociopolíticos e econômicos do país. Os TE se inserem nas ações do cuidado direto, no auxílio ao enfermeiro no planejamento da assistência. Entendem como sendo estruturas norteadoras de promoção de saúde, no curso, conhecimento teórico científico, políticas de saúde, exercício profissional, reflexões das ações técnicas, técnicas, parâmetros legais para promoção de saúde. Afirmaram que há disciplinas específicas voltadas para criança e adultos. Porém, há conteúdo específicos sobre criança, adolescente, adulto, idoso e outros. Os TE são percebidos como agentes transformadores na promoção da saúde.

\footnotetext{
Os professores apresentam muita didática e são qualificados, proporcionam aos alunos entrar em campo estágio com condições de associar os conhecimentos de sala de aula com a realidade encontrada (DI 46).

Em distintos momentos é possível exercer diferentes ações (DO 4).

Os TE serão tarefeiros apenas se desejarem, pois não são formados nesta perspectiva (DO 5).
}

A atuação do TE deve superar a execução de procedimentos técnicos, envolvendo orientação e acompanhamento do trabalho de enfermagem em grau 


\section{Aillbapẫ}

ISSN: 1984-6444 | http://dx.doi.org/10.5902/1984644441514

auxiliar e participação no planejamento da assistência de enfermagem, o que requer um perfil profissional que extrapole o saber fazer. Embora os conhecimentos específicos sejam indispensáveis para atuação profissional, os discentes necessitam aprender a transformar o saber adquirido em algo significativo para sua atuação profissional, desenvolvendo competências por meio reflexivo e para que venha a ser um profissional compromissado com a qualidade da assistência (SILVA et al. 2018).

Os discentes afirmaram que o processo formativo Ihes proporciona observar, ouvir, falar, ler, pensar, refletir e fazer. Percebem-se mais preparados para atuarem na atenção primária, e instrumentalizados para o cuidado integral do ser humano. A formação favorece a atuar mais nas áreas clínica e na saúde do adulto, do idoso, da mulher, e da criança e em urgências e emergências. Demonstraram compreender o significado do processo saúde/doença, se sentem instigados a correlacionar os conhecimentos formativos com o cotidiano real.

Além dos procedimentos atribuídos, saber ouvir as queixas, saber informar, em casos dúvidas (DI 21).

Fazer um cuidado humanizado, visando sempre o bem-estar dos pacientes (DI 34).

Ouvir, analisar, cuidar, dentro das competências (DI 39).

O curso nos proporciona uma visão geral do ser humano, para que nós possamos atuar de forma integral (DI 17).

O curso abrange todas as áreas, por isso se aprende um pouco de cada (DI 56).

Os discentes também relataram como funções específicas dos TE ter competência profissional, prestar cuidado ao indivíduo, a família e a coletividade. Atuar na prevenção, promoção e atenção à saúde, promovendo conforto, segurança, tranquilidade ao usuário. Atuar em equipe, com amor, empatia, solidariedade, respeito, carinho, humanização, ética, de forma científica e técnica. Saber ouvir, analisar o contexto, observar, passar segurança, garantir o cuidado integral, aplicar os conhecimentos e técnicas aprendidas na formação. Relataram como ser estruturante da promoção de saúde Políticas de saúde e exercício profissional, 


\section{Uism \\ $\sim$

ISSN: 1984-6444 | http://dx.doi.org/10.5902/1984644441514

atualizações e capacitações, conhecimentos teóricos, científicos e técnicos. Que se sentem seguros para atuar na profissão com os conhecimentos técnicos científicos desenvolvidos no curso. $E$ percebem os TE como agentes de saúde transformadores e colaboradores.

Cuidar do paciente e tudo que está ao seu redor (família) e também o local de trabalho (DI 1).

Amor pelo ato de cuidar, simplesmente cuidar (DI 11). Promoção, atenção e prevenção (DI 16).

É a equipe de enfermagem que dá apoio 24 horas para os usuários, o técnico entra para somar neste cuidado e contribuir da melhor forma (DI 18). Entendo promoção de saúde como meios para prevenir, cuidar, ensinar, reeducar a população (DI 31).

Nós da saúde, por meio do cuidado, levamos soluções para os pacientes, para a população [...] (DI 60).

Os TE são fundamentais, pois são responsáveis pelo bom atendimento na saúde, por transmitir conforto, segurança, tranquilidade, conhecimentos, [...] participar do processo de educação para a saúde (DI 5).

As atitudes devem ser articuladas aos conhecimentos e habilidades, para que a tríade das competências se faça presente, favorecendo a prestação de uma assistência holística e humana, além de propiciar um perfil de profissionais ativos, críticos e reflexivos (SILVA, 2018, p. 70).

\section{Considerações finais}

Foi possível responder a questão norteadora do estudo, bem como alcançar os objetivos propostos. Os discentes aderiram mais ao aceite para participarem do estudo do que os docentes. Suponha-se que esta disparidade tenha sido pela sobrecarga dos professores e que aos alunos o projeto foi apresentado em horário de aula e quem aceitou a participar, já efetuou sua colaboração neste momento e espaço, sem necessidade de ocupar mais tempo de sua rotina.

Os documentos norteadores destes cursos demonstraram que o processo formativo está alicerçado nas noções de competências de acordo com as concepções do referencial teórico adotado. Constatando que trabalham com a potencialidade dos alunos e com transposição didática, fazendo com que o processo de ensino aprendizagem seja considerado de alta complexidade agregando sentido e valor a formação, tornando o ensino significativo para a vida. $O$ desenvolvimento de competências proporciona entender as dimensões humanas, promove uma 


\section{Aillbapẫ

ISSN: 1984-6444 | http://dx.doi.org/10.5902/1984644441514

sociedade mais igualitária, reconhecendo as vivências dos alunos e a importância destas para a sua relação com mundo do trabalho e sociedade, ressaltando a indissociabilidade entre educação geral e profissional.

Foi possível perceber que alguns dos indicativos e caminhos apontados no referencial teórico para o desenvolvimento de competências no ensino profissional são contemplados como: uso de situações problemas em níveis de complexidade crescentes, tecnologias como ferramentas para as aulas, docentes capacitados, a educação entendida como processo permanente, métodos avaliativos diversos e descentralizados dos tradicionais (provas), aulas mais interessantes, desafiadoras, articulação dos conhecimentos, multidisciplinaridade do ensino, pesquisa e extensão, realização de prática em local de provável atuação profissional (estágios em lócus) favorecendo a complementaridade entre teoria e prática. Há o incentivo ao pensamento crítico, atitudes colaborativas, sustentáveis, autonomia, empreendedorismo, pro atividade, empatia, desenvolvimento contínuo.

As competências profissionais prioritárias e as especificas contempladas nos resultados, apontam que favorecem aos TE compreenderem e atuarem de forma eficaz no processo saúde/doença. Assumindo de vez o status de agentes transformadores nos contextos que atuarem, influenciando o desenvolvimento político e socioeconômico do país.

O processo formativo profissional dos TE realizado nas escolas estudadas demonstra impulsionar os futuros profissionais a ultrapassarem as demandas de mão-de-obra do mercado de trabalho pela sua formação humana e cidadã. Assim, o processo de ensino aprendizagem ao contemplar 0 desenvolvimento de competências (prioritárias e profissionais), adquire um sentido mais amplo, com possibilidades de contribuição com a produção de saúde individual, coletiva e pública.

Neste estudo não foram citadas como competências específicas relacionadas às técnicas procedimentais, por se entender que dar maior valorização a estes conhecimentos possa se incorrer no risco da formação ficar frágil no que tange ao cuidado integral e humanizado. Para desenvolver estas competências técnicas é preciso desenvolver competências profissionais específicas, sem seguirem o modelo 


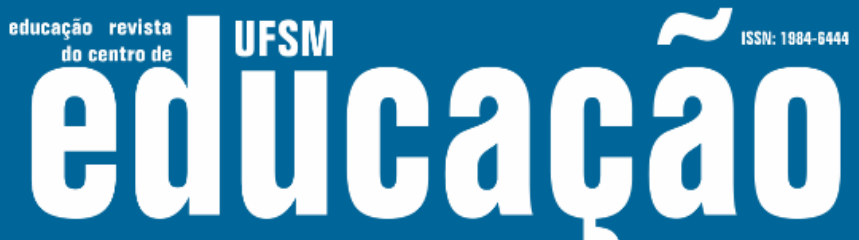

ISSN: 1984-6444 | http://dx.doi.org/10.5902/1984644441514

biomédico. Assim, o foco das discussões foram o desenvolvimento de competências de forma ampla, o "saber saber", o "saber fazer", o "saber ser", analisar as situações, mobilizar os conhecimentos prévios e novos, desenvolvimento de capacidade de organizar o pensar para a tomada de decisão e resolução de forma contextualizada, ética, humana, cientifica e técnica, todas articuladas entre si e correlacionadas. Os profissionais que tiverem seu processo de formação pautado no desenvolvimento de competências com esse viés terão condições de se adaptarem a variabilidade dos contextos laborais, contemplando as diferenças culturais, sociodemográficas e tecnológicas do mundo do trabalho.

Não se está menosprezando as técnicas, nem as tecnologias, mas entendese que a partir do desenvolvimento de competências no processo de formação os TE terão condições para se adequarem as realidades que forem atuar profissionalmente, inclusive buscando a continuação de sua qualificação de forma autônoma, para contemplarem as novas situações que se apresentarem em sua jornada laboral.

Por tanto, cabe enfatizar a importância de discussões amplas e aprofundadas sobre o processo de formação dos TE e seus métodos, para proporcionar crescimento do processo de ensino aprendizagem, contribuindo cada vez mais para que esta categoria evolua profissionalmente. Além desta evolução ser necessária para atender as demandas, os TE por serem em maior número, por prestarem a assistência direta, entre outros fatores implícitos no seu exercício profissional, no Brasil, caracterizam a profissão da enfermagem perante a sociedade, podendo se dizer que até mais que os enfermeiros.

\section{Referências}

BARDIN, Laurence. Análise de Conteúdo. Lisboa, Portugal; Edições 70, LDA, 2011.

BRASIL, Constituição da República Federativa do Brasil de 1988. Disponível: http://www.planalto.gov.br/ccivil_03/Constituicao/Constituicao.htm. Acesso em: 20 abril. 2018. 


\section{usm

ISSN: 1984-6444 | http://dx.doi.org/10.5902/1984644441514

PERRENOUD, Philippe. Construir competências é virar as costas aos saberes? In:

Pátio - Revista Pedagógica, Porto Alegre, n. 11, p. 15-19, nov. 1999b.

PERRENOUD, Philippe.10 novas competências para ensinar. Porto Alegre: ARTMED, 2000.

PERRENOUD, Philippe; THURLER, Monica Gather. As competências para ensinar no século XXI: a formação dos professores e o desafio da educação. 1. ed. Porto Alegre: ARTMED, 2002b.

SILVA, Munyra Rocha et al. COMPETÊNCIAS DOS PROFISSIONAIS TÉCNICOS DE ENFERMAGEM: o que esperam os enfermeiros gestores?. Rev. Enfermagem em Foco, v. 9, n. 4, fev. 2019. ISSN 2357-707X. Disponível em: http://revista.cofen.gov.br/index.php/enfermagem/article/view/1335/482. Acesso em: 01 dez. 2019.

\section{(ㅇ) $(1) \Theta$}

This work is licensed under a Creative Commons Attribution-NonCommercial 4.0 International (CC BY-NC 4.0) 